\title{
EDITORIAL
}

\section{A window into immunoglobulin quantitation and plasma cell disease: antigen epitopes defined by the junction of immunoglobulin heavy and light chains}

\author{
Leukemia (2013) 27, 1-2; doi:10.1038/leu.2012.201
}

Protein electrophoresis (PEL) and immunofixation electrophoresis (IFE) assays form the hub of laboratory testing for multiple myeloma and related plasma cell proliferative diseases. The secreted monoclonal proteins ( $M$ proteins) act as serological 'tumor' markers, and the electrophoretic assays identify M proteins for diagnosis as well as quantitate these markers for monitoring clinical course and response to therapy. ${ }^{1}$ These electrophoretic assays, however, have difficulty identifying and quantitating certain types of $M$ proteins. The most glaring example is the detection and quantitation of monoclonal free light chains (FLCs). Until the serum FLC assay became available, screening panels employing serum and urine PEL and IFE studies were less sensitive for FLCs. Further, urine studies for monitoring disease in patients with light-chain-only myeloma, oligosecretory myeloma, and other oligosecretory plasma cell disorders such as light-chain (AL) amyloidosis were quite cumbersome. In 2001 Bradwell et al. reported quantitative serum assays for $\kappa$ and $\lambda$ FLCs. ${ }^{2}$ The $\kappa$ to $\lambda$ FLC ratio obtained from these assays has proved to be remarkably sensitive for detecting light-chain diseases, and the absolute FLC concentration has been effective for monitoring these diseases. ${ }^{3,4}$ Further, as an unexpected benefit, the FLC ratio was also found to be prognostic for monoclonal gammopathy of undetermined significance (MGUS), smoldering multiple myeloma (SMM), AL amyloidosis, multiple myeloma and solitary plasmacytoma. ${ }^{5-8}$ It is also replacing the urine PEL and IFE when screening for monoclonal plasma cell disorders., ${ }^{9,10}$ As a result, within the last 10 years, the quantitative serum FLC assay has joined PEL and IFE assays and nephelometric measurement of intact immunoglobulins (lg) as part of the basic laboratory panel for the diagnosis, prognosis and monitoring of patients with plasma cell disorders. ${ }^{4}$ However, additional weaknesses remain in our ability to detect and monitor this complex spectrum of disorders. First is the inability to recognize or quantitate small $M$ proteins that migrate in the $\beta$ fraction or $\gamma$ fraction among polyclonal Igs. Second is the difficulty in ascertaining clonality and monitoring in some patients with PEL migration patterns that are so diffuse that electrophoretic markers are not useful indicators of clonality for monitoring relapse. ${ }^{11}$ Finally, even with multiple prognostic markers, accurate determination of risk of progression is still an issue in premalignant plasma cell disorders such as MGUS and SMM. One potentially useful prognostic marker in this regard is the suppression of uninvolved lgs by the monoclonal plasma cell population. However, this has traditionally been difficult to measure with precision.

An immunoassay that recognizes the combination of Ig heavy and light chains (HLC) was described in 2009.12 This assay (Hevylite; The Binding Site, Birmingham, UK) separately quantitates $\lg G \kappa, \lg G \lambda, \lg A \kappa, \lg A \lambda, \lg M \kappa$ and/or $\lg M \lambda$. The quantitation of lgs by isotype-specific light chains allows the same approaches as have been used for FLCs, that is, the ratio of the HLC pairs (for example, $\lg G \kappa / \lg G \lambda$ ) may provide diagnostic information regarding clonal proliferation, and ratios plus quantitation of individual HLC can aid in disease monitoring. In fact, the Hevylite assay appears to help address the weaknesses discussed in the preceding paragraph.

In this issue of Leukemia, there are three articles that have systematically explored the clinical utility of HLC assays. ${ }^{13-15}$ The results of these studies also provide additional biological insights into the pathogenesis of myeloma. Ludwig et al. and Bradwell et al. show that the diagnostic sensitivity for HLC-pair ratios in myeloma is comparable to PEL and IFE. In the study by Ludwig et al., the HLC-pair ratio obtained using the Hevylite assay was more sensitive for monitoring minimal residual disease than PEL plus IFE in some patients. Further, in both studies, highly abnormal HLC-pair ratios were prognostic for progression-free survival, and the combination of $\beta-2$ microglobulin and HLC-pair ratio was a more powerful prognosticator than $\beta-2$ microglobulin plus albumin. The third study is from our group, and it investigates the role of HLC assays in MGUS. This study focused on the use of $\mathrm{HLC}$ assays to measure monoclonal and polyclonal HLC separately as a novel approach to identifying heavy-chain isotype-specific immunoparesis as a predictor of progression in MGUS. IgG plasma cell clones were found to suppress polyclonal IgG synthesis much more efficiently than $\operatorname{lgA}$ and $\lg \mathrm{M}$ secretion. However, more importantly, HLC-pair suppression (that is, suppression of $\operatorname{lgG\kappa }$ in $\operatorname{lgG} \lambda$ MGUS) was an independent predictor of progression to myeloma. Unlike the myeloma studies, we found that the diagnostic sensitivity of the Hevylite assay was lower than that of IFE: $97 \%$ in IgA MGUS, $90 \%$ in IgM MGUS and $56 \%$ in IgG MGUS. This suggests a more limited use of $\mathrm{HLC}$ assays as a diagnostic tool in investigating patients for the presence or absence of clonal plasma cell disorders than would be suggested by the myeloma studies. Still, the high sensitivity for $\lg \mathrm{A}$ and $\lg \mathrm{M} M$ proteins should prove useful for monitoring $\lg \mathrm{A}$ and IgM proteins migrating within the $\beta$ fraction.

Collectively, these reports provide the first systematic set of data on a novel assay to measure lgs by HLC isotypes. The HLC assays allow new ways to examine plasma cell biology and disease. We are able to identify abnormalities that were previously hidden from our view, as indicated by the selective suppression of polyclonal lgG plasma cells by the monoclonal IgG plasma cells. Based on the studies reported in this issue, we can conclude that the Hevylite assay may be useful in monitoring of patients with IgA myeloma and oligosecretory myeloma, where the precise quantity of the $M$ protein is typically not adequately measured by either PEL or traditional quantitative Ig studies. Second, the assay may be of value in identifying $M$ proteins with broad electrophoretic migratory patterns. Third, the data suggest that isotypespecific HLC-pair suppression (suppression of $\operatorname{lgG\kappa }$ in $\lg G \lambda$ MGUS) is a predictor of progression in MGUS, and that it can take place years prior to the overt malignant transformation. Although the latter finding and the putative underlying mechanisms are fascinating from a biological standpoint, we need more data before this is considered to be of clinical utility. Finally, further work is needed to clarify the role of the Hevylite assay for minimal residual disease detection and as a prognostic factor in myeloma in the context of rapidly evolving therapy. ${ }^{16}$ 


\section{CONFLICT OF INTEREST}

Dr Katzmann has received travel funds from The Binding Site, the manufacturer of the Hevylite assay. The authors declare no other conflict of interest.

\section{JA Katzmann ${ }^{1}$ and SV Rajkumar ${ }^{2}$ ${ }^{1}$ Division of Clinical Biochemistry and Immunology, Mayo Clinic, Rochester, MN, USA and ${ }^{2}$ Division of Hematology, Mayo Clinic, Rochester, MN, USA E-mail: rajkumar.vincent@mayo.edu}

\section{REFERENCES}

1 Kyle RA, Rajkumar SV. Criteria for diagnosis, staging, risk stratification and response assessment of multiple myeloma. Leukemia 2009; 23: 3-9.

2 Bradwell AR, Carr-Smith HD, Mead GP, Tang LX, Showell PJ, Drayson MT et al. Highly sensitive, automated immunoassay for immunoglobulin free light chains in serum and urine. Clin Chem 2001; 47: 673-680.

3 Drayson M, Tang LX, Drew R, Mead GP, Carr-Smith H, Bradwell AR. Serum free light-chain measurements for identifying and monitoring patients with nonsecretory multiple myeloma. Blood 2001; 97: 2900-2902.

4 Dispenzieri A, Kyle R, Merlini G, Miguel JS, Ludwig H, Hajek R et al. International Myeloma Working Group guidelines for serum-free light chain analysis in multiple myeloma and related disorders. Leukemia 2009; 23: 215-224.

5 Kyrtsonis MC, Vassilakopoulos TP, Kafasi N, Sachanas S, Tzenou T, Papadogiannis A et al. Prognostic value of serum free light chain ratio at diagnosis in multiple myeloma. Br J Haematol 2007; 137: 240-243.

6 Kumar S, Zhang L, Dispenzieri A, Van Wier S, Katzmann JA, Snyder M et al. Relationship between elevated immunoglobulin free light chain and the presence of high translocations in multiple myeloma. Leukemia 2010; 24: 1498-1505.

7 Rajkumar SV, Kyle RA, Therneau TM, Melton III LJ, Bradwell AR, Clark RJ et al. Serum free light chain ratio is an independent risk factor for progression in monoclonal gammopathy of undetermined significance (MGUS). Blood 2005; 106 812-817.

8 Dispenzieri A, Kyle RA, Katzmann JA, Therneau TM, Larson D, Benson J et al. Immunoglobulin free light chain ratio is an independent risk factor for progression of smoldering(asymptomatic)multiple myeloma. Blood 2008; 17: 785-789.

9 Katzmann JA, Dispenzieri A, Kyle R, Snyder MR, Plevak MF, Larson DR et al. Elimination of the need for urine studies in the screening algorithm for monoclonal gammopathies by using serum immunofixation and free light chain assays. Mayo Clin Proc 2006; 81: 1575-1578.

10 Katzmann JA, Kyle RA, Benson J, Larson DR, Snyder MR, Lust JA et al. Screening panels for detection of monoclonal gammopathies. Clin Chem 2009; 55: 1517-1522.

11 Donato LJ, Zeldenrust SR, Murray DL, Katzmann JAA. 71-year-old woman with multiple myeloma status after stem cell transplantation. Clin Chem 2011; 57: 1645-1648.

12 Bradwell AR, Harding SJ, Fourrier NJ, Wallis GL, Drayson MT, Carr-Smith HD et al. Assessment of monoclonal gammopathies by nephelometric measurement of individual immunoglobulin kappa/lambda ratios. Clin Chem 2009; 55 1646-1655

13 Ludwig H, Milosavljevic D, Zojer N, Faint JM, Bradwell AR, Hübl W et al. Immunoglobulin heavy/light chain ratios improve paraprotein detection and monitoring, identify residual disease and correlate with survival in multiple myeloma patients. Leukemia 2012, (this issue)

14 Bradwell A, Harding S, Fourrier N, Mathiot C, Attal M, Moreau P et al. Prognostic utility of intact immunoglobulin $\lg ^{\prime} \kappa / \lg ^{\prime} \lambda$ ratios in multiple myeloma patients. Leukemia 2012, (this issue).

15 Katzmann JA, Clark R, Kyle RA, Larson DR, Therneau TM, Melton III LJ et al. Suppression of uninvolved immunoglobulins defined by heavy/light-chain pair suppression is a risk factor for progression of MGUS. Leukemia 2012, (this issue).

16 Lacy MQ, Hayman SR, Gertz MA, Short KD, Dispenzieri A, Kumar S et al. Pomalidomide (CC4047) plus low dose dexamethasone (Pom/dex) is active and well tolerated in lenalidomide refractory multiple myeloma (MM). Leukemia 2010; 24 1934-1939. 